\title{
Dialectic and the Structure of Argument
}

\author{
R.C. Pinto \\ University of Windsor
}

\section{I: Introduction.}

1. There is a passage early in the Gongias in which Socrates points out one of the differences between rhetoric and dialectic. Polus has been scoffing at an unpopular view which Socrates holds, and Socrates says to him:

\begin{abstract}
...you are trying to refute me orator-fashion like those who fancy they are refuting in the law courts. For there one group imagines it is refuting the other when it produces many reputable witnesses to support its statements whereas the opposing party produces but one or none. But this method of proof is worthless toward discovering the truth, for at times a man may be the victim of false witness on the part of many people of repute. And now practically all men, Athenians and strangers alike, will support your statements, if you wish to produce them as witnesses that my view is false.....Yet $\mathrm{l}$, who am but one, do not agree with you, for you cannot compel me to; you are merely producing many false witnesses against me in your endeavor to drive me out of my property, the truth. But if I cannot produce in you yourself a single witness in agreement with my views, I consider that I have accomplished nothing worth speaking of in the matter under debate; and the same, I think, is true for you also, if $\mathrm{I}$, one solitary witness, do not testify for you and if you do not leave all these others out of account. 1
\end{abstract}

When one practices dialectic, one seeks to persuade-indeed to compel-just one other person to become a witness in agreement with one's views. And in doing so, one must leave "all these others"-Jowett's translation has "the rest of the world" - out of account.

What I want to read out of this passage is that in the Platonic view, dialectic-or dialectical interchange-is strictly an affair between two parties, that the views of any third party are quite beside the point. In fact, I want to take this passage further than I have any right to do, and to suppose that Socrates is saying that the persuasion which transpires in dialectical interchange recognizes no rule or standard that is not acknowledged by the parties to the interchange themselves.

2. A set of propositions constitutes a set of premisses for a conclusion $p$ if and only if someone puts them forward as premisses for $\mathbf{p}$ in the course of arguing for $\mathbf{p}$. And a person argues for $p$ if and only if that person puts forward one or more propositions as premisses for $\mathbf{p}$. You can't make much sense of the notions of premiss and conclusion unless you've got the notion of arguing; and you can't make much sense of the notion of arguing unless you got the notions of premiss and conclusion.

Now I submit that to make sense of the notion of arguing for a conclusion, you've also got to have the notion of a point at issue between two persons-a point at issue being simply any proposition that is affirmed by one of them but not by the other. Arguing occurs in a context in which there are points at issue and addresses itself to one or more of those points. Typically an arguer is attempting either to argue for a proposition which he affirms but someone else does not, or against a proposition which someone else affirms and he does not. Typically, as well, an arguer's argument meets with challenge or counter-argument or both. And such challenge or counterargument is often responded to with challenge or further argument or counter-counter-argument, and so on.

When two parties interact over a point at issue in the extended way l've just described, they are engaging in what I call a dialectical interchange. When an argument occurs in 
the context of a dialectical interchange, understanding it and appraising it will almost always require understanding its place and function within that dialectical interchange. The consideration of the individual argument will go hand in hand with the consideration of the dialectical interchange in which it occurs.

Not every argument occurs within or gives rise to a dialectical interchange. But any argument can give rise to a dialectical interchange-and it will, if the person to whom it's addressed disputes or counters it. It might just turn out to be the case, therefore, that the intelligent consideration of any argument whatsoever requires consideration either of an actual dialectical interchange in which it occurs or of one or more potential dialectical interchanges in which it might occur. I can't give you a strong reason for thinking that's so, but I confess to a strong suspicion that it is so.

3. What I want to offer you in this paper are two suggestions-admittedly tentative ones-about how best to approach the understanding and appraisal of an argument which is being considered in the context of an actual or potential dialectical interchange.

My suggestions are:

(1) the most promising organizing notions for treating arguments in the context of dialectical interchange are the correlative notions of presumption and burden of proof;

(2) that one ought to hold out, as best and as long as one can, against the idea that there are "objective" standards or ground rules against which it is appropriate to measure and appraise arguments occurring in the context of a dialectical interchange.

\section{Il: Presumption and Burden of Proof.}

4. The parties to a dialectical interchange assume the roles of arguer and respondent. Moreover, they typically switch roles, the original arguer becoming respondent to the other's argument, then becoming arguer again, and so on. When an arguer presents a set of propositions as premisses addressed to some point at issue, respondent must either concede or refuse to concede the members of that set. If respondent refuses to concede a premiss, it becomes (of course) a point at issue. If respondent concedes all premisses, either she concedes the conclusion as well, or she does not. If she concedes the conclusion, it ceases to be a point at issue. Let us say that the interchange is at an end if and only if there are no longer any points at issue. Interchanges may be terminated, or course, even though they are not at an end.2

Let us imagine respondent signalling refusal to concede a

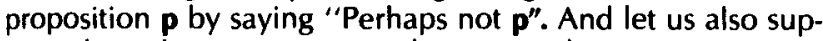
pose that whenever a respondent concedes a proposition $q$ but refuses to concede $\mathbf{p}$, she is committed to "Perhaps $\mathbf{q}$ and not $\mathbf{p . "}$

Employing just these skeletal notions we can begin to identify one sort of virtue which an argument may have-the virtue of being an effective or compelling argument. If I offer $\mathbf{q}$ as an argument for $\mathbf{p}$, and you are unwilling to say "Perhaps not q" and also unwilling to say "Perhaps $\mathbf{q}$ and not $\mathbf{p}^{\prime \prime}$, then you have no choice but to concede $\mathbf{p}$. An argument is effective or compelling (for or to a given respondent) just where respondent is unwilling or unable to say that perhaps its premiss is false and is unwilling to say that perhaps its premiss is true but its conclusion false.

Consider for a moment the suggestion that effectiveness so conceived is the only, or the principal, virtue of arguments. The suggestion would, of course, make the strength or value of arguments relative to the individuals to whom those arguments are addressed. But that consequence of the suggestion is surely not an outrageous one.

Many would object to the suggestion, however, on the grounds that it demands too little of arguments. Bad arguments, they will say, can be effective or compelling in this sense. And there is something to this objection. There are indeed arguments which are compelling or effective with certain respondents only because of faults or defects (such as, for example, gullibility) on the part of those respondents. For the suggestion to become plausible, then, the notion of effectiveness would have to be emended to rule out such cases.

But there is, it seems to me, a more serious objection to the suggestion-namely, that it demands too much of arguments. Outside of mathematics and mathematics-like disciplines, arguments seldom compel assent in the manner envisaged above. In the typical case, argument issues not in assent but in counterargument. In the typical case, argument does not bring dialectical interchange to an end; rather, it alters its course.

It seems to me that we can begin to get a handle on these matters if we conceive of the principal virtue of good arguments in the following way: a good argument is one which requires a respondent either to assent or to counterattack. And it seems to me, further, that we can express this by saying that a good argument is one which creates a presumption in favor of its conclusion and shifts the burden of proof to the one who would dispute that conclusion.

We may define "presumption" in the following way:

A proposition or statement has the status of a presumption at a given juncture of an interchange if and only if at that juncture any party who refuses to concede it is obliged to present an argument against it-that is to say, is obliged either to concede it or to make a case against it.

And in line with this, we may say that where a proposition has the status of a presumption, then the burden of proof lies with anyone who refuses to concede it.

It is enormously fruitful, I believe, to view arguments in a dialectical interchange as attempts to confer on their conclusions the status of a presumption-or, what is to say the same thing, to shift the burden of proof to those who would dispute them. For it offers a way of conceptualizing the ineluctable tentativeness of argument as dialectically contextualized and also a way of focusing our questions about the status of the norms by reference to which we appraise arguments as good and bad.

If good arguments are those which confer upon their conclusions the status of presumptions, and if to do that is to bring it about that respondents have obligations to concede or to refute, then a good argument is one which creates such an obligation. The question, "What are the norms of good argument?" can then be interpreted as a question about the grounds we can have for saying of an argument that it creates such an obligation.

5. Rescher, whose book Dialectics has made me aware of the fruitfulness of these notions, has written as follows:

A means for appraisal and evaluation is a fundamental precon- 
dition of rational controversy. Without the existence of objective standards of adequacy, rational controversy is inherently impossible. Argument is pointful as a rational process only if the extent to which a "good case" has been made out can be assessed in retrospect on a common, shared basis of judgment. ${ }^{3}$

Rational dialectic is possible only in the presence of an established methodology of probative assessment: not, to be sure, agreement on the facts, but on the machinery for the evaiuation of arguments-on the probative mechanisms for the weighing of evidence, the appraisal of plausibility, etc. A shared procedure for the assessment of plausibility and the allocation of presumption thus emerges as a critical factor in dialectic -indeed, as one of the critical presuppositions of rationality throughout the context of rational discussion. ${ }^{4}$

The question I want to ask is whether this view is forced upon us, or whether we can keep open the possibility that dialectical interchange is subject to no external constraints.

\section{III: Do there have to be "objective standards" for assessing arguments?}

6. Let me admit at the start that it won't make sense to talk about arguments as imposing obligations to concede or dispute unless we recognize something like a standard or rule by reference to which such obligations are said to arise. My question concerns the origin and status-or better, the source of validity-of such standards or rules. Let me also indicate right at the start that $I$ refer to such standards or rules as presumption policies, and that the position I would like to be able to maintain is that presumption policies are as a matter of fact made up by those who engage in argument and that they get the only force or validity they have from the fact that those who engage in argument choose to endorse them.

I certainly am in no position to prove that what l'd like to maintain about these matters is in fact the truth. The best I can do is to try to render it plausible. And the only way I can think of to render it in the least plausible is to look at some kinds of examples in which presumption policies come into play and to suggest from these examples two things about them. First, that such policies are as a matter of fact open to challenge within the context of dialectical interchange (i.e., that challenges to such policies are - or seem to be - coherent). Second, that a challenge to some such policy need not bring that interchange to an impasse.

What I propose to do is to examine two types of argument which most of us would agree create a presumption in favor of their conclusion, to see what sort of rule or policy could under-lie the claim that they do create presumption and to speculate about the import of a challenge to such an underlying policy. I shall look first at arguments that trade on the supposition that something is the "usual case", and second at arguments that purport to establish hypotheses by citing "confirmation" of those hypotheses.

7. "Usual case" arguments. The following "facts" create presumptions; that is to say, anyone who concedes those "facts" must either concede or counter the "conclusions" indicated:

(1) The fact that an item appears in a reputable newspaper (e.g., the New York Times) creates a presumption that the item is true.

(2) The fact that someone is a human being creates the presumption that he or she has the properties of a "normal" human being.

(3) The fact that a sample is randomly drawn from a population $\mathbf{P}$ creates, for any property $\mathbf{Q}$, the presumption that the sample is representative of population $\mathbf{P}$ with respect to property $\mathbf{Q}$.
Notice that each of the statements above approximates to the form:

(4) For any value of $x$, if anyone concedes that $x$ is $A$ then $s /$ he must either concede that $\mathbf{x}$ is $B$ or counter the claim that $x$ is B.

Let me use the phrase "presumption policy" to denote substitution instance of (4). Now I claimed that the "facts" mention in (1), (2), and (3) create certain certain presumptions; but not everyone need agree with me. That is to say, I endorse those presumption policies, but it need not be the case that everyone endorse them.

Let us say that presumption policy "licenses" an inference.

Notice that endorsing a presumption policy which licenses the inference from "It's an $A^{\prime \prime}$ to It's a $B^{\prime \prime}$ is quite difference from supposing that all $A^{\prime}$ 's are B's. Indeed, none of us would suppose that all items in reputable newspapers are true, or that every human being has all the properties of a "normal" human being or that every randomly drawn sample is representative of the population from which it's drawn with respect to every property. Moreover, if we were prepared to make such suppositions, we would have no need to revert to presumption policies in order to license the inference from "It's an A" to "It's a B".

If $m y$ argument trades on a certain presumption policy, and you endorse that very policy, you will be prepared either to dispute my premiss or concede my conclusion or to adduce counter-evidence against that conclusion. But what if you simply concede my premiss but refuse to endorse my conclusion? I say, "I felt her forehead; it's warm; she must have a fever", and you say "I grant her forehead is warm; but that doesn't mean she has a fever." Now if you usually accept such evidence as evidence of a fever, I can accuse you of some kind of inconsistency and ask you for an explanation of why you accept such evidence for such a conclusion in other cases, but don't accept it in this case. But suppose you don't ever accept such evidence for such a conclusion. I may point out to you that others accept such evidence and ask you why you think their practice is a mistake or why your practice differs from theirs. Notice that you might have a perfectly good answer to my question. You might point out that there's a better way to determine whether someone has a fever than by feeling her forehead; you might say that it's your practice to defer judgment until a temperature is taken with a thermometer. I might challenge your claim that requiring a thermometer reading is a better practice. Or I might concede that in general it's preferable, but argue that in this case no thermometer is available, that my "evidence" is the best we've got to go on and urge that we're not in a position to defer judgment. And so on.

What I've tried to sketch here is a possible course of development in a dialectical interchange in which there is disagreement with respect to what is to count as evidence. The first point I want to make is that such disagreements frequently occur and occur in such a way that they don't constitute an insuperable impasse in the dialectical interchange. Indeed, cases like the one I'm imagining provide an example of how an issue concerning the standards for argument appraisal can arise within a dialectical situation and how such an issue sometimes can be handled within that very situation itself.

My second point concerns the kinds of consideration that are brought to bear in such situations. I want to label them pragmatic considerations. To bring out why I choose this label (and what I mean by it), imagine another variant on the interchange l've just described. In this variant, you don't propose a 
better way to determine whether someone has a fever; you say instead that you yourself don't recognize any way of determining whether someone has a fever. That's not very plausible with this example, but might not be at all implausible if the issue were (as it might be in a debate on abortion) what's to count as evidence that a living organism has an "immortal soul". Your refusal to count anything as evidence (i.e., prima facie evidence) that something is a such-and-such has the practical consequence that there will be no mutually agreed upon way to settle the question of whether something is suchand-such. That in turn gives scope for argument over whether that consequence is desirable, whether we can get on, or get on as well, with such-and-such's relegated to the realm of "mere opinion" that lies beyond the reach of rational discussion.

In the epistemological literature there are examples of such pragmatically based arguments for endorsing what I call presumption policies. Reichenbach's argument for his brand of induction (if any way of predicting the future works, induction works; therefore if we don't endorse induction, we won't have any method for predicting the future) is well known. $5 \mathrm{H}$. $H$. Price's defense of the prima facie credibility of testimony is not so well known. 6

8. Let me turn now to the second kind of argument I mentioned earlier: arguments that purport to establish hypotheses by citing "confirmation" of those hypotheses.

I hope you'll agree with me that it's totally unacceptable to say that whenever a proposition p entails another proposition $\mathbf{q}$, then finding $\mathbf{q}$ true confirms or supports $\mathbf{p}$. One does a bit better if one says something like the following: If $B$ is our background information and $E$ some ascertainable event not derivable from or rendered probable by $\mathbf{B}$, and if $\mathbf{B}$ and $\mathbf{H}$ entails $\mathbf{E}$, then finding that $\mathbf{E}$ obtains confirms $\mathbf{H}$. One does a bit better that way, but not much. For there's ad hocery to be contended with and there are so-called implausible hypotheses to be contended with. Now I submit that to get any very defensible formulation of the "principle of confirmation" along anything like these lines, one needs to build in some restriction on the sorts of hypotheses that are eligible for confirmation and that the prospects of stating such restrictions in a way that's purely formal but still has bite are pretty slim. The truth of the matter seems to me to be something like this: we think a hypothesis is supported by "confirming evidence" of a certain kind just where it is a hypothesis of some recognizable type and we believe it is desirable to be able to derive evidence of that kind from some hypothesis of that type. Thus if the hypothesis is an explanatory hypothesis, it will be an explanatory hypothesis of one or another recognizable type-perhaps mechanical, perhaps teleological, and so on. At this particular juncture of history, for example, not many of us have much regard for teleological explanations of the behavior of what we take to be inanimate objects. I doubt, therefore, that very many of us would be disposed to grant any weight at all to evidence, no matter how extensive, derived from the hypothesis that the purpose of tidal waves is to control the growth of human populations. ${ }^{7}$

Actually, the "type" or kind to which we can usefully assimilate proposed hypotheses is likely to be narrower in scope than just "mechanical" or "teloeological," and is indeed likely to be identifiable only by reference to historically concrete instances as "examples" of the kind in question. A given hypothesis is likely to be put forward as a psychological hypothesis or a biological hypothesis or a chemical hypothesis, and so on. And if we're asked to explain what we mean by $a$ :psychological (or biological or chemical) hypothesis, we can probably not do much better than to say that they are those of the sort that are propounded by psychologists (or chemists or biologists)-having in mind certain more or less specific individuals whom we consider psychologists (or biologists or chemists).

I want to suggest, then, that arguments from the confirmation of a hypothesis trade on presumption policies which approximate more or less to the following form:

If $H$ is a hypothesis of kind $K$ and $X$ is a state of affairs of kind $E$, and if $\boldsymbol{H}$ together with background information $B$ implies that $X$ obtains, then anyone who concedes that $X$ obtains ought either to concede that $H$ is true or else to provide an argument against $\mathbf{H}$, provided that there is no other hypothesis of kind $\mathbf{K}$ which is consistent with B and which together with B implies that $X$ obtains.

The proviso that there be no other hypothesis of the same kind is important for two reasons. First, it helps make sense of the fact that one can remove the presumption which confirming evidence confers on a hypothesis by formulating an alternative hypothesis which is consistent with the "known facts" (background information B) and which can do the very job which the original hypothesis was intended to do (is of the same kind $\mathbf{K}$ as the original hypothesis and is as capable of "explaining" $X$ as was the original hypothesis). Second, the proviso sheds light, I think, on the force which such arguments have. For where the proviso is met, $H$ will be the only hypothesis of kind $\mathbf{K}$ available for "explaining" the fact that $X$ obtains. The alternatives open to respondent will be to concede $\mathbf{H}$ or to do without a " $\mathrm{K}$ " explanation of $\mathbf{X}$. The force of the argument will therefore be proportional to the importance or value of having such an explanation of $\mathbf{x}$.

Now suppose a party to a dialectical interchange offers an argument which trades on some such presumptive policy; and suppose the other party concedes the premiss yet dismisses. the hypothesis without contesting it. The dialectical interchange need not, in such cases, reach an impasse. For the argument can now turn to the quesion of whether it's a Good Thing to seek hypotheses like the one in question to explain evidence like that in question. And the parties to such a debate can again turn to pragmatic considerations to support or dispute the contention that explanation of the sort attempted by the arguer is a worth-while undertaking.

\section{IV: Conclusion.}

9. Suppose that what I would like to maintain is true; suppose there are no fixed standards for judging arguments as they occur in dialectical contexts. What implications would that have for the enterprise of Informal Logic, insofar as that enterprise seeks to be an art or science of argument appraisal?

The implication, I think, would be this. One cannot appraise an argument from a position one takes up outside the context of the dialectical interchange in which that argument occurs. One cannot appraise an argument in the role or office of neutral judge. Appraising an argument requires one to step into the dialectical interchange, become party to it, become a participant in it. Informal logic, insofar as it seeks to be an art of argument appraisal, would turn out to be the very art of arguing itself. Plato had a name for it. He called it the art of dialectic. 
Notes

1. Plato, Gongias, 471-72. The translation is that of W.D. Woodhead, from Edith Hamilton and Huntington Cairns, eds., The Collected Dialogues of Plato (Pantheon Books, 1961).

2. The decision to terminate a dialectical interchange or rational discussion can have considerable practical and 1 or theoretical import, for it leaves the discussants with the beliefs and commitments which they happen to have at the point at which discussion ceases. Compare Dennet's remarks on this as it applies to deliberation, in Brainstorms (Cambridge, Ma.: M.I.T. Press, 1981), pp. 293-95.

3. Nicholas Rescher, Dialectics: a Controversey-Oriented Approach to the Theory of Knowledge (Albany: State University of New York Press, 1977), p. 43.

4. Ibid., p. 45.

5. See, for example, Hans Reichenbach, Experience and Prediction (University of Chicago Press, 1938), pp. 348-63.
6. H.H. Price, Belief (London: George Allen 0 Unwin, 1969), Lecture 5.

7. In a rather different context, and in pursuit of conclusions quite unrelated (or perhaps even opposed) to the view I'm propounding here, Bas van Fraassen has suggested that a "typology of causes" or classification of different sorts of explanatory undertaking is needed to make sense of explanational asymmetries and to provide a general theory of explanation. See his "A Re-examination of Aristotle's Philosophy of Science", Dialogue, 1980; and The Scientific Image (Oxford: Clarendon Press, 1980), pp. 130-32.

R.C. Pinto, Department of Philosophy, University of Windsor, Windsor, Ontario, Canada N9B 3P4

\section{Fourth Annual \& Second International Conference On CRITICAL THINKING \& Educational Reform \\ at the \\ Center For Critical Thinking \& Moral Critique, Sonoma State University}

July 9-13, 1984

CRITICAL THINKING AS THE FOUNDATION OF LIBERAL EDUCATION: $K-U$

\section{Featured Speakers}

Henery Steele Commager, the dean of American historians

Kenneth Burke, Distingulshed critic of American letters

Nell Postman, outspoken critic of American education

Matthew Lipman, philosopher of education, founder of Philosophy for Children

Robert Ennis, Director of Illinois Thinking Project, founder of Cornell Critical Thinking Test

David Perkins, Specialist in Problem Solving Theory, Harvard School of Education

John Sabinl and Maury Sllyer, following up Milgram's Exp. On Unquestioning Obedience to Authority

Aichard W. Paul, Director of the Center For Crittical Thinking and Moral Critlaue

Edward D'Angelo, Specialist In the Theory \& Teaching of Critical Thinking

Donald Lazere, Author, Journalist, Critic

Ralph Johnson $\mathrm{J}$. Anthony Blair, editors of the journal of Informal Logic, U. of Windsor

Harvey Slegel, Philosopher of Education, specialist in Theory of Critical Thinking

Edward Maynard Glaser, founder of the Watson-Glaser Critical Thinking Test

lan Wright, Carol LeBar, Jerrold Combs, specialists in Moral Reasoning Programs

Daniel Taylor, Senior Vice-President of the College Board

and many other authors, scholars, \& specialists in critical thinking \& publlc education

\begin{tabular}{|c|c|c|}
\hline $\begin{array}{l}\text { - National Test } \\
\text { - Research Centers on } \\
\text { Thinking Skills } \\
\text { - Subject Matter Specialists } \\
\text { - Censorship \& Media } \\
\text { - Eiteracy } \\
\text { - Emotional, Moral, \& } \\
\text { Intellectual Autonomy }\end{array}$ & $\begin{array}{l}\text { - Staff Development } \\
\text { - The relationship between } \\
\text { Cognitive \& Affective } \\
\text { - Global Perspective } \\
\text { - Writing \& Thlnking Programs } \\
\text { - Cross-disciplinary Thinking } \\
\text { - Skills } \\
\text { Detection of Bias \& } \\
\text { Ethno-centricity }\end{array}$ & $\begin{array}{l}\text { - Critique of Everyday Life } \\
\text { - Training vs Education } \\
\text { - Moral Reasoning } \\
\text { - Oberedience to Authority } \\
\text { - Administration Problems } \\
\text { - The Milgram Experiment } \\
\text { - Five Days of Papers, } \\
\text { Workshops and Panels }\end{array}$ \\
\hline \multicolumn{3}{|l|}{ Registration } \\
\hline $\begin{array}{l}\text { \$90.00 For One Person } \\
\$ 160.00 \text { For Two Persons } \\
\text { From Same Institution } \\
\$ 210.00 \text { For Three Persons } \\
\text { From Same Institution } \\
\text { Fourth Person From Same } \\
\text { Institition Free } \\
\text { \$50.00 Each Additional Person }\end{array}$ & $\begin{array}{l}\text { - On-Campus Housing Available } \\
\text { - Send Registration Fee To: } \\
\text { Richard W. Paul, Director } \\
\text { Center For Critical Thinking } \\
\text { \& Moral Critique } \\
\text { Sonoma State University } \\
\text { Rohnert Park, CA } 94928\end{array}$ & $\begin{array}{l}\text { - Make Checks Payable To: } \\
\text { Foundation: Center For } \\
\text { Critical Thinking } \\
\text { - Additional Information Upon } \\
\text { Request }\end{array}$ \\
\hline
\end{tabular}

